\title{
Concepções e práticas no ensino de leitura em inglês no ensino médio
}

\author{
Conceptions and practices in the teaching of English reading in high \\ school
}

\author{
Daniel Mateus O'Connell* \\ Academia da Força Aérea \\ Dirce Charara Monteiro** \\ Universidade Estadual Paulista
}

\begin{abstract}
Resumo Tendo em vista os resultados insatisfatórios no ensino de leitura em língua inglesa, bem como a escassez de investigações sobre o tema no Ensino Médio, esta pesquisa tem como objetivo identificar as concepções teórico-metodológicas de duas professoras de Inglês desse nível de ensino sobre as diferentes abordagens de leitura e como essas concepções se fazem presentes em sua prática. Nesta pesquisa de natureza qualitativa os dados foram obtidos por meio da observação da prática docente e da realização de entrevistas com as professoras participantes. Os resultados da pesquisa poderão oferecer indicadores para ações voltadas para a melhoria do ensino da leitura em inglês como língua estrangeira.
\end{abstract}

PALAVRAS-CHAVE: Ensino de leitura; Ensino médio; Língua inglesa; Estratégias de leitura; Concepções e práticas docentes.

Abstract Considering the unsatisfactory results regarding the teaching of English reading, as well as the scarcity of research on this theme in high school level, this research aims at identifying the theoretical and methodological conceptions of two high school English teachers about the different approaches to reading and how these conceptions are present in their practice. In this qualitative research data were obtained by observing the teachers' practice and by interviewing both teachers. The results of this research can offer indicators for activities aimed at improving the teaching of reading English as a foreign language.

KEYWORDS: Reading education; High school; English language; Reading strategies; Conceptions and teaching practices. 


\section{Introdução}

Dentre os muitos problemas enfrentados no ensino e aprendizagem de línguas estrangeiras (LE), podemos mencionar a falta ou escassez de recursos didático-pedagógicos, a redução da carga horária, um elevado número de alunos por sala e o pouco investimento e incentivo a programas de formação inicial e continuada de professores. O número reduzido de aulas de línguas estrangeiras modernas (LEM) leva os professores a assumirem várias turmas diferentes para poderem completar sua carga horária, o que certamente dificulta o seu trabalho. Além das atividades de ensino, é necessário lembrar que os professores também estão envolvidos em tarefas de coordenação e gestão da escola (GIMENO SACRISTÁN, 2000) que reduzem o tempo de preparação das aulas.

Nesse contexto, e considerando a importância do desenvolvimento da competência leitora, nosso interesse voltou-se para aprofundar nosso olhar para o ensino de leitura em inglês no ensino médio. $\mathrm{Na}$ busca por pesquisas que contemplassem o tema proposto, no Banco de Teses e Dissertações da CAPES bem como nas pesquisas produzidas nos programas de pós-graduação do estado de São Paulo, foram encontradas, no período de oito anos, de 2005 a 2012, 34 pesquisas que tratam de problemas relacionados à leitura em língua inglesa. No entanto, desse conjunto, somente 11 tiveram como contexto de investigação o Ensino Médio, não tendo sido localizada nenhuma pesquisa que tivesse como temática as práticas de ensino de leitura em língua inglesa nesse nível de ensino tendo como ponto de referência a Nova proposta curricular de língua estrangeira moderna do Estado de São Paulo (SÃO PAULO, 2008).

Essa escassez de estudos aliada a nossas inquietações sobre as concepções e práticas dos professores encarregados de efetivar a proposta curricular paulista, principalmente no que se refere ao ensino da leitura na etapa final da educação básica, levaram-nos à formulação da seguinte pergunta de pesquisa:

De que modo o professor do ensino médio da rede pública conduz sua prática de ensino de leitura levando em consideração suas concepções teórico-metodológicas acerca dos processos de ensino e aprendizagem de línguas estrangeiras, suas concepções de leitura bem como o novo currículo de LEM do estado de São Paulo?

Com base no questionamento acima, propusemos os seguintes objetivos para esta pesquisa que consistiu em nossa tese de doutorado (O'CONNELL, 2015): a) investigar as concepções teórico-metodológicas desses professores acerca da leitura e da proposta curricular paulista; b) observar como as aulas de leitura em língua inglesa, tendo como norte a proposta curricular paulista, são conduzidas por duas professoras do Ensino Médio.

Apresentamos, a seguir, algumas considerações sobre a proposta curricular de LEM paulista (SÃO PAULO, 2008) que servirão de base para analisar as concepções e as práticas observadas. 


\section{A proposta curricular de línguas estrangeiras modernas do estado de São Paulo}

A trajetória do ensino e aprendizagem de línguas estrangeiras modernas caracteriza-se por duas principais orientações metodológicas que direcionaram a matriz curricular dessa disciplina no decorrer dos últimos anos, a orientação de ênfase estruturalista e a orientação de ênfase comunicativa. Para os estruturalistas, abordagem predominante na década de 70 e meados de 80 , o ensino baseava-se em princípios de aprendizagem behaviorista e preconizava um ensino das estruturas linguísticas de uma forma mecânica e descontextualizada, privilegiando atividades de repetição e memorização. Já a abordagem comunicativa que fundamentava a proposta curricular de 1988 (SÃO PAULO,1988) visava à aquisição da competência comunicativa, valorizando o domínio das quatro habilidades - listening, speaking, reading and writing-- relacionando a forma gramatical (usage) ao seu uso (use) para a comunicação. Canale (1996) e Canale and Swain (1980) detalharam o conceito de competência comunicativa que compreende as competências gramatical, sociolinguística, discursiva e estratégica.

Por um conjunto de razões que não serão aprofundadas neste artigo, a proposta de base comunicativa não foi bem-sucedida na sua aplicação, seguindo-se a ela um modelo baseado na variedade dos gêneros textuais. Assim, a partir de 2008, foi implantada, no estado de São Paulo, uma proposta baseada nos letramentos múltiplos, com base em Kern (2000), amparada nas relações existentes entre ambos os princípios que sustentam a abordagem estruturalista e comunicativa, o saber e o fazer. O saber refere-se ao conhecimento da estrutura gramatical de uma língua, e o fazer refere-se às funções comunicativas de uma língua:

O conhecimento linguístico, ou seja, o saber não se sustenta sem o fazer. Desse modo, não se trata mais de privilegiar a gramática ou as funções comunicativas, mas de promover o conhecimento de si e do outro, traduzindo em diferentes formas de interpretação do mundo, concretizadas nas atividades de produção oral e escrita, desenvolvidas em cada uma das etapas da escolarização. (SÃ̃ PAULO, 2008, p. 43).

A nova proposta, baseada nos postulados teóricos de Kern (2000), constitui um avanço em relação às anteriores, defendendo um aprendizado por meio de atividades práticas que possibilitem ao aluno ligar seu universo de vivência aos seus estudos, promovendo sua autoconstituição e inserção social.É por meio desse processo de letramento que o indivíduo se torna um cidadão crítico e atuante, capaz de utilizar a escrita e a leitura para se expressar livremente no meio social em que vive. Celani et al. (2005) também defendem que os alunos devem participar do processo de ensino e aprendizagem não como meros receptores de informações, mas como seres conscientes, críticos e participantes ativos desse processo.

A proposta de letramentos múltiplos de Kern (2000) sugere a ampliação do espectro dos textos trabalhados em sala de aula. $\mathrm{O}$ autor propõe o estudo e a análise de diversos gêneros textuais, sejam escritos ou falados, que contemplem aspectos mais significativos e práticos, como, por exemplo, discursos políticos, anúncios, cartas, filmes, jornais, artigos de revistas, vídeos, musicais, entrevistas, piadas, editoriais e outros. 
Segundo o autor, o aluno letrado é aquele que se comunica eficientemente com grupos diferentes de pessoas em uma vasta gama de situações e contextos sociais, usando uma variedade de discursos linguísticos apropriados e específicos para cada cenário.

Nesse sentido, essa iniciativa governamental do estado de São Paulo estimula atividades que proporcionem momentos significativos de mudança no processo de ensino e aprendizagem do cidadão, por meio da ampliação do repertório de práticas de leitura com base nas relações entre oralidade e escrita. Os aprendizes são expostos a uma série de situações que propiciam a construção da autonomia necessária para o aprendizado. Desse modo,

[...] é possível promover tanto o engajamento em práticas de leitura e escrita mediadas pela oralidade quanto a construção da autonomia necessária para que o aluno desenvolva sua capacidade de aprender a aprender uma língua estrangeira. (SÃO PAULO, 2008, p. 43).

É justamente esse o foco da abordagem de ensino e aprendizagem baseada em Kern (2000). O ensino contempla situações que encorajam a leitura e a escrita reflexiva desde o início da aprendizagem da língua estrangeira. Os aprendizes são expostos a diferentes contextos para que possam estar preparados para lidar com as ambiguidades e incertezas que ocorrem no dia a dia dos cidadãos.

A conscientização crítica da linguagem faz parte do aprendizado nesse contexto (FIGUEIREDO, 2000), visando não apenas a integrar o aluno a uma sociedade já constituída, mas também a emancipá-lo socialmente, fazendo com que ele não somente atue na ordem social como também a modifique quando necessário. Nesse sentido, torna-se extremamente necessário o desenvolvimento da conscientização crítica de alunos e também de professores, com o objetivo de criar perspectivas que possam implicar na reconstrução e não apenas na reprodução de modelos já rotulados anteriormente. Práticas sócio-político-educacionais de emancipação são de grande importância no processo educacional de qualquer língua. Portanto,

[...] tanto as escolhas metodológicas quanto a escolha de conteúdos a serem abordados devem dar visibilidade ao diálogo entre o conhecimento escolar, sua formação como cidadão e suas relações com o mundo do trabalho, ampliando sua afinidade com os saberes para além das antigas perspectivas reducionistas que se limitavam apenas à preparação do educando para o mercado de trabalho ou para $\mathrm{o}$ ensino superior. (SÃO PAULO, 2008, p. 44).

O novo currículo proposto para o ensino de LE no estado de São Paulo (SÃO PAULO, 2008) constitui um avanço no sentido de conciliar elementos importantes das abordagens anteriores, alinhando-se às propostas de ensino de língua materna, no sentido de estruturar as atividades de ensino em torno da pluralidade textual. As críticas têm recaído principalmente no seu processo de elaboração e implementação (BERNARDINO, 2010), que não considerou as vozes dos professores nem os saberes necessários para que esse currículo se efetivasse na ação (GIMENO SACRISTÁN,2000). 


\section{Metodologia}

Para a consecução dos objetivos propostos, optamos por realizar uma pesquisa qualitativa de cunho etnográfico, pois pretendíamos investigar o contexto no qual as professoras participantes estavam inseridas por meio de alguns instrumentos de pesquisa, principalmente a observação de aulas de duas professoras do ensino médio, da rede pública de ensino de uma cidade do interior paulista, para analisar suas práticas docentes e entrevistas, para identificar suas concepções sobre ensino de leitura. Os resultados obtidos nas observações e nas entrevistas serão apresentados nas próximas seções.

\section{Concepções de leitura das professoras}

A professora $A a^{1}$ revelou, na entrevista, possuir algumas concepções tradicionais na abordagem dos textos em sala de aula, como, por exemplo, valorizar a tradução como atividade importante para avaliar a compreensão da leitura. Ana explicita no Excerto 1 que foi orientada a trabalhar no método tradicional, o que, certamente, para ela, incluía atividades de tradução.

\section{Excerto $\mathrm{n}^{\circ} 1$}

E: A senhora tem licenciatura dupla?

P: Tenho.

E: Inglês, português.

P: Isso. Então, nós fomos orientados a trabalhar no método tradicional, né.

E: Sim.

P: Então, quando a gente saiu da escola, foi a mesma forma. E houve uma mudança muito grande. Houve uma mudança muito grande...

E: No decorrer dos anos?

P: É. Só que a gente não foi preparada para isso.

(Trecho da entrevista semiestruturada, 27/03/14)

Essa necessidade de trabalhar a tradução de textos durante as aulas de língua inglesa parece advir de sua formação profissional inicial bem como de sua trajetória de aprendizagem de língua inglesa e está de acordo com resultados de Bomfim (2006). Verifica-se que ela tem consciência das mudanças ocorridas no ensino de LE após sua formação inicial, mas reclama da falta de orientação para alterar sua prática.

É importante esclarecer que o uso da tradução não é um procedimento recriminado pela nova proposta curricular de línguas estrangeiras modernas do estado de São Paulo (SÃO PAULO, 2008). Porém, nessa perspectiva, deve ser um incentivo para que o aluno possa escrever sua própria versão de um texto lido, demonstrando assim sua capacidade de expressão de uma forma independente.

Ana ainda destaca a importância do conhecimento lexical para a entrada no mercado de trabalho. Tal fato é realmente importante para o jovem na busca por um emprego, porém, como destaca a nova proposta, o ensino não pode se limitar 
às "antigas perspectivas reducionistas" (SÃO PAULO, 2008, p. 44), devendo ir muito além da preparação para o mercado de trabalho e para a universidade. Nesse sentido, a formação explicitada na nova proposta propõe a constituição de cidadãos acima de tudo, cidadãos conscientes de sua responsabilidade no mundo e prontos para fazer exercer seus direitos e deveres.

Ainda no tocante à leitura, a professora Ana é incentivada pelo pesquisador a especificar os passos ou procedimentos utilizados na realização da leitura dos textos em sala de aula. Além do conhecimento linguístico, evidencia-se, no Excerto n², que ela, ao descrever sua prática, menciona algumas orientações contidas na proposta curricular paulista e que estão mais de acordo com as necessidades dos aprendizes.

\section{Excerto $n^{\circ} 2$}

E: Como é que a senhora trata, de uma forma geral, o ensino da leitura em sala de aula? A senhora adota alguns passos na abordagem dos textos?

P: É. A gente, geralmente, nós conversamos um pouco antes, né. Eu falo um pouco antes do começo, lá pelo título, né. Sobre o que o texto está falando?

$\mathrm{E}:$ É a ativação do conhecimento prévio, né?

P: É. E aí, o ensino médio é meio difícil de conversar (risos!!!).

E: Sim. A senhora tinha falado.

P: Então, a gente vai falando, depois eu peço para eles dentro do... ah, vamos ver lá o primeiro parágrafo. Quais as palavras que vocês conhecem? Depois, eu pergunto para eles, tem alguma palavra lá que vocês acham que seja parecida com o português, com as palavras em português, né?

E: Cognatos, né?

P: É. Os cognatos. Vamos ver se elas realmente têm o mesmo significado. E a gente vai fazendo esse trabalho primeiro. Depois, aí eu falo, olha a gente vai ler o texto e eu vou ajudar vocês na tradução porque eles não conseguem, né.

E: Sim.

P: Então, a gente faz uma leitura do texto para eles saberem do que se trata o texto. E aí, eles partem para os exercícios que vêm na apostila que sempre tem perguntas ali, e informações, né, retiradas do texto.

(Trecho da entrevista semiestruturada, 27/03/14)

Verifica-se, no trecho acima, que a professora Ana tem conhecimento de algumas estratégias de leitura, embora não consiga utilizar os termos corretos para nomeá-las. Para Braatz (2012), Guedes (2012), Solé (2009), Kern (2000), Leffa (1999) e Kato (1999), as dimensões metacognitivas são ferramentas importantes no processo da leitura, pois possibilitam que o leitor faça uso de certos recursos, de forma consciente, para poder auxiliá-lo nas dificuldades e obstáculos encontrados no percurso da leitura, contribuindo para a sua autonomia como leitor.

Ao descrever as atividades por ela desenvolvidas, a professora Ana afirma que faz uso do conhecimento prévio dos discentes antes de iniciar a leitura do texto. Ela solicita aos alunos que observem o título e digam "sobre o que o texto está falando." 
Essa atividade de pré-leitura, segundo Munhoz (2000) e Solé (2009), é de grande valia na abordagem de um texto, pois ajuda o aluno a inferir e predizer o assunto do mesmo. A antecipação da temática da leitura contribui e incentiva o leitor a refletir sobre o conteúdo do texto antes mesmo de lê-lo. Para Kern (2000), a ativação do conhecimento prévio pode contribuir para o desenvolvimento do senso crítico do aluno, no sentido de que após a leitura, é possível que ele reflita sobre seu conhecimento prévio de um modo diferente, atribuindo-lhe novos valores e significados.

Por meio da ativação do conhecimento prévio, Ana também explora características do texto que contribuem para a formação de um leitor consciente. A análise do título dos textos é um dos recursos utilizados pelo leitor na compreensão e interpretação, "Eu falo um pouco antes do começo, lá pelo título, né." Souza (2005) destaca que as marcas tipográficas dos textos como títulos, gravuras, gráficos, ilustrações, charges e outros, são elementos importantes utilizados pelo autor no decorrer do mesmo.

Além da ativação do conhecimento prévio e das pistas tipográficas, evidencia-se que a professora Ana também recorre ao uso de cognatos, "tem alguma palavra lá que vocês acham que seja parecida com o português?” Os cognatos, segundo Paiva (2005), são palavras bastante parecidas com as da língua portuguesa, tanto na forma escrita quanto na forma falada e podem contribuir enormemente para a compreensão do texto.

Da mesma forma que a professora Ana, a professora Jane ${ }^{1}$ afirma gostar de ler textos na língua portuguesa e inglesa. No entanto, assim como vários professores, queixa-se de que, embora goste muito de ler, não tem muito tempo disponível. Tal fato se confirma no trecho a seguir:

\section{Excerto $n^{\circ} 3$} na língua

E: Bem, uma pergunta. Em geral, você gosta de ler, não só especificamente

inglesa, mas na língua portuguesa também?

P: Gosto. Não tenho muito tempo. (risos!!!)

E: Qual é a sua carga horária aqui? É de quantas horas?

P: Vinte e seis aulas.

$\mathrm{E}$ : Vinte e seis aulas?

P: É. Tudo picado.

E: Entendi.

P: (risos!!!) Fico manhã, tarde e noite. (risos!!!)

E: É bastante cansativo!

(Trecho da entrevista semiestruturada, 03/09/14) 
Como a professora Jane assumiu suas aulas em caráter emergencial no meio do primeiro semestre de 2014, suas aulas foram distribuídas nos três períodos, em horários nada convenientes. Por isso, afirma que sua rotina diária é "bastante cansativa" e, em razão dos horários intercalados, não há muito tempo para se dedicar à leitura. Além do número excessivo de alunos por sala de aula, falta de recursos didático-pedagógicos, diminuição da carga horária das Línguas Estrangeiras (LE) e o investimento limitado em programas de formação inicial e continuada de docentes, Avelar (2004) também aponta a jornada cansativa dos professores de uma forma geral.

Outro problema mencionado por O'Connell (2008, p.108) que afeta o trabalho não apenas de professores de Inglês bem como das demais disciplinas, refere-se à necessidade de assumir vários cargos em escolas diferentes na tentativa de "garantir seu próprio bem-estar e de sua família.”

No que tange ao gosto pela leitura em língua inglesa, a professora Jane apresenta uma visão bastante adequada no sentido de apontar a necessidade de atualização constante, conforme pode ser evidenciado no trecho a seguir:

\section{Excerto $n^{\circ} 4$}

E: Em relação à língua inglesa. Você acredita que tem facilidade em ler textos na língua inglesa?

P: Acredito que sim. Eu acho que o inglês, a gente tem que estar sempre estudando, sempre lendo, sempre aprimorando, né. Agora, dando aula de inglês, eu sou obrigada a tá procurando. Quando eu tenho que dar aula, eu já gosto de ir bem preparada para as perguntas. Porque eles querem saber o que tudo significa.

(Trecho da entrevista semiestruturada, 03/09/14)

Esse posicionamento da professora demonstra seu interesse em continuar aperfeiçoando seu conhecimento, especialmente o linguístico, adquirido, segundo ela, principalmente por meio da prática da leitura. Ademais, sua fala também evidencia seu comprometimento com o ensino ao dizer que "Agora, dando aula de inglês, eu sou obrigada a tá procurando."

O depoimento da professora Jane vai ao encontro dos princípios da nova proposta curricular de línguas estrangeiras modernas do estado de São Paulo (SÃO PAULO, 2008) no sentido de valorizar um ensino comprometido com a formação cidadã e emancipadora do indivíduo, objetivo primordial da orientação de letramentos múltiplos, teorizada por Kern (2000), o que será evidenciado na análise de sua prática.

\section{As práticas de leitura}

A prática da professora Ana revela, na maioria das vezes, coerência com suas concepções teórico-metodológicas acerca dos processos de ensino e aprendizagem de línguas estrangeiras nas quais mobiliza práticas mais tradicionais que se mesclam a práticas mais condizentes com as propostas pelo novo currículo. $\mathrm{O}$ excerto $\mathrm{n}^{\circ}$ 5 exemplifica a alternância de práticas mais interativas, sugeridas pelo novo currículo, 
com o recurso à tradução, herança de sua trajetória de aprendizagem de línguas bem como de sua formação inicial para o magistério.

\section{Excerto $n^{\circ} 5$}

A professora inicia a atividade incentivando os alunos a dizer o que entendem da primeira pergunta. Os alunos respondem que a pergunta indaga se ele já esteve em uma universidade. A professora confirma a compreensão dos alunos ao destacar os vocábulos you e university. Ela diz "Isso, tem o you e tem o university". A próxima pergunta é lida pela docente em voz alta e imediatamente traduzida. Em seguida, ela dá uma pausa esperando possíveis respostas, que são dadas por vários alunos.

\section{(Trecho da Aula 2,18/08/14)}

Outro exemplo de alternância está na mobilização de práticas mais tradicionais na correção das tarefas realizadas, momento em que a professora não dá voz aos alunos e na opção por práticas mais condizentes com abordagens mais contemporâneas de ensino de línguas estrangeiras, como, por exemplo, quando estimula os alunos a se posicionarem criticamente sobre um texto lido, estabelecendo relações com sua vida pessoal.

Assim como a professora Ana, a prática da professora Jane também parece, na maioria das vezes, estar em sintonia com suas concepções teórico-metodológicas acerca dos processos de ensino e aprendizagem de línguas estrangeiras constantes da proposta curricular paulista. Assim, por exemplo, ao iniciar uma unidade que trata da escolha da profissão, considerando que se trata de uma turma do terceiro ano do ensino médio, a docente aproveita para justificar o assunto dizendo aos alunos que esse tópico se mostra bastante relevante para eles já que todos estão prestes a fazer a escolba da profissão futura. A aproximação do conteúdo com a realidade dos discentes é uma prática recomendada na abordagem de letramentos múltiplos, base da nova proposta.

Porém, diferentemente da primeira docente, revela, em sua prática, na maior parte das aulas, um avanço na incorporação de alguns princípios da abordagem de letramentos múltiplos, como, por exemplo, quando ela propõe situações que oferecem oportunidades para que o aluno possa se posicionar e se manifestar perante diversas questões controversas e polêmicas. Ela dá voz aos alunos e os orienta em situações nas quais o discente necessita de supervisão para poder enxergar nos textos lidos valiosos princípios e valores que nem sempre são percebidos devido à falta de maturidade e de desenvolvimento intelectual.

\section{Considerações finais}

Constatamos, por meio das entrevistas e da observação das aulas, que as duas professoras colaboradoras têm concepções resultantes de suas trajetórias de formação bem como da experiência profissional de cada uma delas. As práticas observadas são coerentes com as suas concepções sobre leitura verbalizadas nas entrevistas. 
No caso da professora Ana, as atividades de leitura desenvolvidas com seus alunos revelam uma alternância entre práticas mais tradicionais e outras preconizadas pelo modelo de letramentos múltiplos de Kern (2000), no qual a proposta curricular paulista se fundamenta. Abordagens mais tradicionais para o ensino de línguas estrangeiras estão presentes em sua prática em situações como, por exemplo, a forma metódica de iniciar suas aulas, fazendo a chamada, vistando a tarefa dos alunos e corrigindo os exercícios de casa. Suas aulas também evidenciam que nem sempre há oportunidades para que os alunos se manifestem e se expressem no decorrer da correção de atividades a respeito de assuntos polêmicos. Além disso, assim como a professora Jane, ela faz uso constante da tradução no decorrer das atividades de leitura.

No entanto, mais frequentes são os momentos em que ela revela, em sua prática, concepções pautadas em princípios característicos de abordagens mais contemporâneas de ensino de línguas estrangeiras, procurando, na medida do possível, proporcionar atividades diferenciadas tendo em vista o perfil e as necessidades dos seus alunos. Um exemplo refere-se ao oferecimento de atividades variadas para trabalhar o vocabulário, pois, segundo ela, alguns alunos assimilam melhor os novos vocábulos por meio de atividades mais tradicionais como a tradução dos mesmos, a leitura controlada ou meras repetições fonéticas. Porém, em sua prática, há momentos em que estimula a compreensão de novos vocábulos por meio do uso das estratégias de leitura como procurar fazer com que os alunos deduzam o significado pelo próprio contexto.

Diferentemente da correção dos exercícios feitos em casa, durante as atividades de leitura realizadas em sala de aula, ela trabalha a capacidade crítica dos alunos, instigando-os a justificarem suas respostas e a se posicionarem quando necessário. Além disso, ela também procura desenvolver as estratégias metacognitivas de leitura durante suas aulas, focalizando no texto a importância das pistas tipográficas, do layout do texto, das pistas morfológicas, propondo a busca de informações específicas (scanning) e explorando as características dos gêneros textuais.

Da mesma forma que a professora Ana, o desempenho da professora Jane também parece estar de acordo com suas concepções teórico-metodológicas acerca dos processos de ensino e aprendizagem de línguas estrangeiras e seus possíveis entendimentos sobre modelos de leitura.

Contudo, apesar de, em algumas ocasiões, realizar atividades pautadas em abordagens mais tradicionais, princípios de abordagens mais contemporâneas de ensino de línguas estrangeiras parecem nortear mais frequentemente sua prática pedagógica. Um exemplo são as inúmeras ocasiões em que ela oferece aos alunos oportunidades para que possam se posicionar e se manifestar durante e após a leitura de textos que abordam questões controversas e polêmicas. Além de dar voz aos alunos ela também se posiciona em situações nas quais o discente necessita de supervisão e orientação para enxergar nos textos valiosos princípios e valores que nem sempre são vistos devido à falta de maturidade e de desenvolvimento intelectual. A docente evidencia em sua prática ter conhecimento da proposta curricular vigente em nosso estado, pois, além de abordar gêneros textuais variados e buscar a formação cidadã dos alunos, ela também utiliza recursos metacognitivos, explorando as estratégias de leitura, ferramentas incentivadas pela nova proposta. 
Embora sua prática reflita conhecimento da nova proposta, assim como a professora Ana, ela também valoriza a tradução dos textos com os alunos em sala de aula. É certo que a proposta curricular vigente incentiva a escrita como forma de reformulação ou interpretação de textos. Porém, as atividades de tradução propostas por ambas não exigem a capacidade de expressar de forma pessoal a compreensão e interpretação dos textos lidos em sala de aula. A professora Jane, por exemplo, trabalha a tradução dos textos sempre em duplas e os alunos não têm a oportunidade de ler o texto individualmente e silenciosamente. Todos os textos são lidos por dois alunos e traduzidos com o auxílio do computador no laboratório de informática. Acreditamos que a necessidade de ambas as professoras trabalharem a tradução em sala de aula se origine tanto de sua própria trajetória de aprendizado da língua inglesa bem como de suas concepções sobre leitura.

Pode-se concluir que a prática das professoras observadas está, pelo menos em parte, de acordo com os princípios da nova proposta baseada nos letramentos múltiplos, especialmente a da professora Jane que procura promover a participação ativa dos alunos, oferecendo oportunidades para que eles se posicionem perante questões importantes suscitadas pela leitura dos textos e que visam ao desenvolvimento da formação cidadã. Fica evidente, em suas aulas, seu conhecimento acerca da abordagem de letramentos múltiplos, base da nova proposta, que, se adequadamente implementada, poderá trazer resultados satisfatórios não apenas para o ensino da leitura, bem como das demais habilidades linguísticas.

É importante apontar que os materiais didáticos utilizados também trazem textos de gêneros variados com orientações valiosas para os alunos e professores, auxiliando o trabalho do professor tanto na conscientizando dos alunos sobre as características dos diferentes gêneros como em relação às estratégias metacognitivas necessárias para a compreensão dos textos lidos.

Os resultados de nossa pesquisa indicam que, antes da implementação de quaisquer propostas curriculares, é necessário que haja iniciativas no sentido de ouvir e de preparar melhor o docente que estará efetivamente promovendo as mudanças em sala de aula. Considerando que a incorporação de novas concepções na prática pedagógica dos professores requer reflexão e amadurecimento, o caminho é a implementação de políticas públicas voltadas para a formação inicial e continuada de professores para garantir que o currículo proposto realmente se efetive na sua prática pedagógica, garantindo os resultados esperados.

Ao elaborar uma proposta dessa natureza, a Secretaria do Estado de São Paulo objetivava, certamente, a melhoria do ensino e aprendizado do aluno egresso das escolas públicas. Para isso, o envolvimento dos gestores e, principalmente, dos professores é fundamental, pois eles também são convidados a desenvolver novas competências e a encarar novos desafios. Entretanto, ainda é cedo para afirmar que a nova proposta está atingindo os seus objetivos e contribuindo positivamente para a formação do indivíduo principalmente no que se refere ao papel da leitura, já que ela se encontra nos seus primeiros anos de implementação e os resultados de propostas curriculares não são rapidamente observáveis e mensuráveis. 


\section{Referências}

AVELAR, F. J. S. Visões e ações de uma professora em serviço: reflexões sobre a construção do ensino de leitura em língua estrangeira. 2004. 178 f. Dissertação (Mestrado) - Universidade Federal de Uberlândia, Uberlândia, 2004.

BERNARDINO, E. A. Análise e implementação da nova proposta pedagógica estadual para o ensino de língua inglesa no ensino fundamental. 2010.137 f. Dissertação (Mestrado em Educação Escolar) - Faculdade de Ciências e Letras, Universidade Estadual Paulista, Araraquara, 2010.

BOMFIM, R. Babel de vozes: crenças de professores de Inglês Instrumental sobre tradução.2006.169 f. Dissertação (Mestrado em Educação). Universidade de Brasília, 2006

BRAATZ, S. C. Uso de estratégias metacognitivas de leitura em alunos da disciplina de inglês instrumental. 2012. 180 f. Dissertação (Mestrado) Universidade Federal do Paraná, Curitiba, 2012.

CANALE, M. From communicative competence to communicative language pedagogy. In: RICHARDS, J. C.; SCHMIDT, R. W. Language and communication. 7.ed. New York: Longman, 1996, p.1-27.

CANALE, M; SWAIN, M. Theoretical bases of communicative approaches to second language teaching and testing. Applied Linguistics, London, v. 1, n. 1, p. 1-47, 1980.

CELANI, M. A. A. et al. ESP in Brazil: 25 years of Evolution and Reflection. Campinas, SP: Mercado de Letras, Educ, 2005.

FIGUEIREDO (2000), C.A. Leitura crítica: mas isso faz parte do ensino de leitura. 2000. 255 f. Tese (Doutorado em Linguística Aplicada) UNICAMP, 2000.

GIMENO SACRISTÁN, J. O currículo: uma reflexão sobre a prática. Porto Alegre: Artmed, 2000 .

GUEDES, A. S. O processamento cognitivo da compreensão na leitura instrumental em inglês no ensino médio profissionalizante. 2012. 178 f. Dissertação (Mestrado) Universidade Federal de Alagoas, Maceió, 2012.

KATO, M. A. O aprendizado da leitura. 5. ed. São Paulo: Martins Fontes, 1999

KERN, R. Literacy and language teaching. Oxford: Oxford University Press, 2000.

LEFFA, Vilson J. O ensino de línguas estrangeiras no contexto nacional. Contexturas, São Paulo, v. 4, p. 13-24, 1999.

MUNHOZ, R. Inglês instrumental: estratégias de leitura - módulo I. São Paulo: Texto Novo, 2000.

O'CONNELL, D. M. Formação do professor: da teoria à prática. Letras \& Letras, Uberlândia, v.24, n.1, p.103-110, jan./jun. 2008.

Concepções e práticas de ensino de leitura em inglês no ensino médio: uma análise da nova proposta curricular de línguas estrangeiras modernas do estado de São Paulo 2015. 231f. Tese (Doutorado em Educação Escolar) - Faculdade de Ciências e Letras da UNESP, 2015.

PAIVA, V.L.M.O. Desenvolvendo a habilidade de leitura In: PAIVA, V.L.M.O.(Org.). Práticas de ensino e aprendizagem de inglês com foco na autonomia. Belo Horizonte: Faculdade de Letras da UFMG, 2005, p. 129-147. 
SÃO PAULO. Proposta Curricular de Língua Estrangeira Moderna - Inglês $1^{\circ}$ grau. São Paulo: SE/Cenp, 1988.

SÃO PAULO. Secretaria de Estado da Educação. Nova Proposta Curricular de LEM. São Paulo: SEE, 2008. 56 p.

SOLÉ, I. Estratégias de leitura. 6.edição Porto Alegre: Artmed, 2009.

SOUZA, A. F.; ABSY, C. A.; COSTA G. C; MELLO, L. F. Leitura em Língua Inglesa: uma abordagem instrumental. São Paulo: Disal, 2005.

\section{Notas}

${ }^{1}$ Nome fictício.

${ }^{2}$ Nome fictício.

* Professor adjunto da Academia da Força Aérea (AFA/FAB), Pirassununga, São Paulo, Brasil.

** Professora doutora da Universidade Estadual Paulista (UNESP), São Paulo, São Paulo, Brasil.

\section{Correspondência}

Daniel Mateus O'Connell - Academia da Força Aérea. Estrada de Aguaí, s/n - Campo Fontenelle, CEP: 13643000 - Pirassununga, SP - Brasil.

E-mail: mateusoconnell@yahoo.com.br -dcharara@terra.com.br

Recebido em 11 de junho de 2016

Aprovado em 31 de outubro de 2016 
